\title{
Soft Handoff Parameters Evaluation in Downlink WCDMA System
}

\author{
A. A. AL-DOURI \\ Electrical Engineering Department \\ Tikrit University
}

\author{
S. A. MAWJOUD \\ Electrical Engineering Department \\ Mosul University
}

Abstract

Mobility is an essential feature of mobile wireless communication systems. Handoff is a feature that deals with the mobility of the user in order to provide seamless phone call when the user cross the cell borders to another one. WCDMA system is the third generation system, implements soft handoff (SHO) technique while hard handoff (HHO) which is used in GSM system. Soft handoff is a technique which allows the user equipment in the overlap region to link with two or more base stations. The effect of soft handoff on the downlink direction of WCDMA will be studied because the downlink is considered as the limiting parameter in CDMA systems. The effect of soft handoff on the most important parameters of the downlink in WCDMA is investigated using simulation. Other related parameters of WCDMA system optimization such as load factor, noise rise, and parameters related to the quality of service like bit error rate (BER) are investigated. The results reveal that a user in soft handoff consumes less power from its serving base station. This reduction in the power leads to reducing the total interference in the cell and hence improving the performance of WCDMA system by reducing the load factor (loading) and noise rise, and increasing the capacity and enhancing the quality of service. Furthermore, the results assure why 2-way soft handoff is commonly used in CDMA system.

Keywords: Mobile System, WCDMA, Handoff, Soft Handoff, Load Factor, BER

تقويم تأثثير المتغيرات في المناقلة السلسة في الاتصال النازل لنظام WCDMA

$$
\text { قسم الهندسة الكهربائية }
$$

$$
\text { عبد المطلب عبد الوهاب الدوري }
$$

$$
\text { المستخلص: }
$$

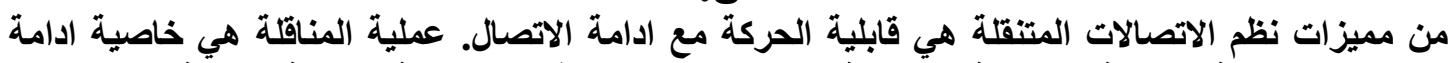

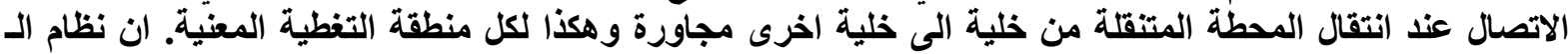
WCDMA

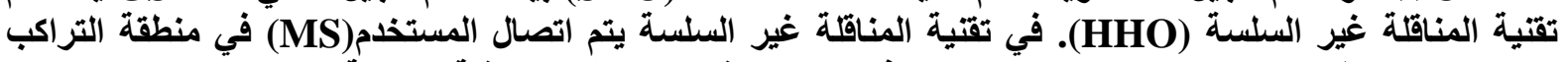

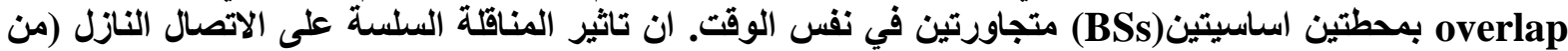

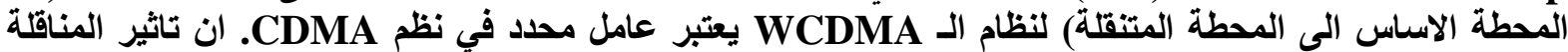

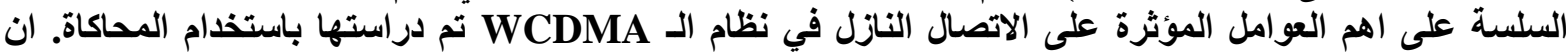

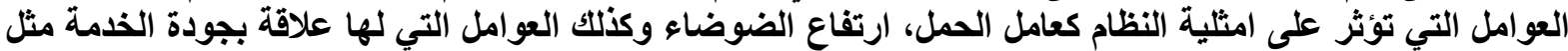

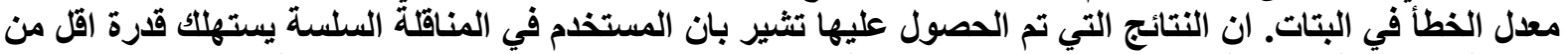

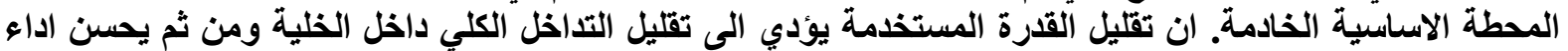

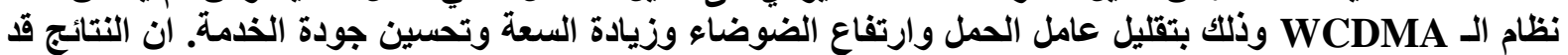

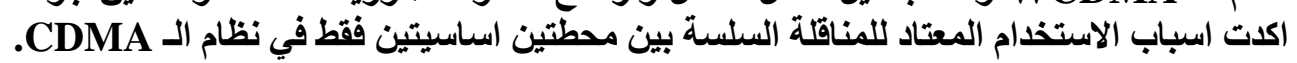




\section{Introduction:}

The last two decades has encountered enormous development in mobile radio communication. The developments started from the first generation $(1 \mathrm{G})$ analog system to the second generation $(2 \mathrm{G})$ digital system. While $1 \mathrm{G}$ can support voice service only, $2 \mathrm{G}$ provides voice service as well as low bit rate data service. The demand for multimedia and high data rate services has led to the development of the third generation $(3 \mathrm{G})$ system, which uses the wideband code division multiple access (WCDMA), a technique which allows to support high data rate services. One of the attractions of cellular systems is the handoff technique. It means that a mobile station (MS) can maintain its connection in cellular networks when it moves from one cell to another adjacent cell. Soft handoff (SHO) is a unique feature in WCDMA system, which is a smooth transition from one cell to another. Frequency reuse of one in CDMA makes it possible for a user at the cell borders to communicate simultaneously with two or more base stations. A user in the soft handoff zone establishes a new link before dropping the old link with the serving base station (BS). The MS combines the received signals from all base stations involved in the soft handoff operation in order to strengthen the received signal and consequently enhancing the performance of the system[1][2][3]. The bit error rate (BER), which is a parameter related to the quality of service (QoS), refers to the information bit error rate i.e. for user bits after decoding, the BER is given as a function of the measured signal-to-interference $\operatorname{ratio}\left(\mathrm{E}_{\mathrm{b}} / \mathrm{I}_{\mathrm{o}}\right)[4]$. For voice the target value is $10^{-4}-10^{-3}[5]$

In [6], the effect of soft and softer handoff on the CDMA system capacity was evaluated according to the average bit energy to interference power spectral density (Eb/Io) which corresponds to bit error rate (BER) of $10^{-3}$. While in [7]Soft handoff gain in WCDMA was estimated and the results revealed that soft handoff improves the capacity of the system while keeping the same quality of service. Downlink soft handoff performance in WCDMA was studied in [8] and the results led to that 2-way soft handoff reduces the required dedicated transmission power up to $3 \mathrm{~dB}$, moreover, soft handoff gain has better value at soft handoff overhead equal to $30 \%$. In [9] the impact of soft handoff on the UMTS system performance is investigated, and the results approved that in downlink, soft handoff improves not only the quality of service but also the overall system capacity.

\section{Mobile Radio Environment and Propagation Model:}

The propagation model used is introduced in [10] is modeled as a product of two components, the path loss and the shadowing attenuation.

Equation (1) represents the path loss as a function of the distance (r) and shadow fading $(\zeta)$ :

$\mathrm{L}(\mathrm{r}, \zeta)=\mathrm{r}^{\mathrm{a}} \cdot 10^{\zeta / 10}$

Where "a" is the path loss exponent $(2<a<6)$ with typical value of 4 in urban area[2], " $\zeta$ " is the attention in decibel due to shadowing which is a log-normal random variable with zero mean and standard deviation " $\sigma$ " with typical value of $8 \mathrm{~dB}$ [3]. 
$\mathrm{L}(\mathrm{r}, \zeta)=10 \mathrm{a} \log (\mathrm{r})+\zeta \quad(\mathrm{dB})$

\section{System Scenario}

The system scenario used consists of seven-cell hexagonal grid, as shown in figure(1). There is one serving $\mathrm{BS}$ at the center and surrounded by six interfering BSs (first tire). The shaded area represents the soft handoff region and the remaining is known as the non-soft handoff region.

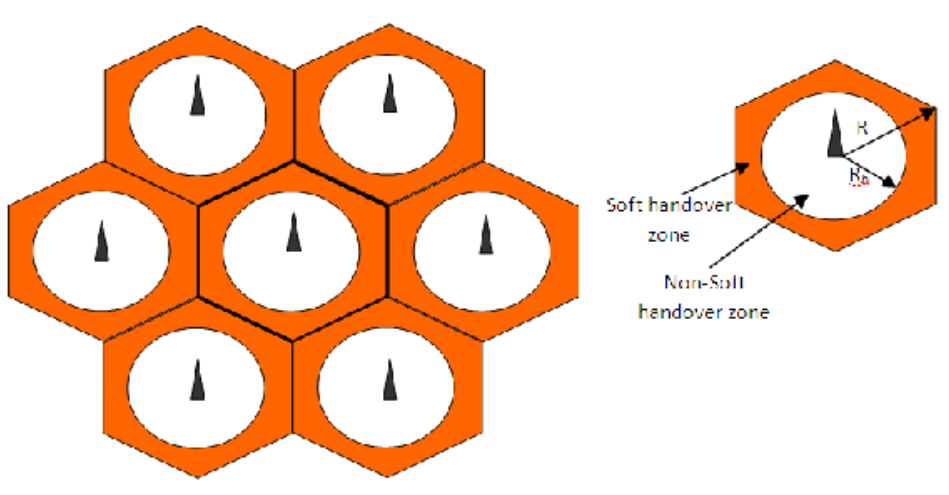

Figure (1) System scenario

\section{Downlink Mathematical Analysis in WCDMA:}

\subsection{Analysis without SHO:}

The downlink analysis starts from the common following equation [3]:

$$
\begin{aligned}
& \left(\frac{E_{b}}{I_{o}}\right)_{i}=\text { Processing gain of user } i \frac{\text { signal of user } i}{\text { Total received power }(\text { excl.own signal })} \\
& \left(\frac{E_{b}}{I_{o}}\right)_{i}=\frac{W}{v R_{b}} \frac{\frac{P_{i 1}}{L_{i 1}}}{\frac{P t_{1}(1-\alpha)}{L_{i 1}}+>_{j=2}^{7} \frac{P t_{j}}{L_{i j}}+P_{N}}
\end{aligned}
$$

Where $\left(\frac{E_{b}}{I_{o}}\right)_{i}$ is the bit energy to interference power spectral density for user $\mathrm{i}, \mathrm{W}$ is the chip rate $=3.84 \mathrm{Mcps}, \mathrm{R}_{\mathrm{b}}$ is the bit rate for user $\mathrm{i}$. It depends on the type of service, $\mathrm{v}$ is the activity factor, $\mathrm{P}_{11}$ is the required transmit power at $\mathrm{BS}_{1}$ allocated for user $\mathrm{i}, \mathrm{Pt}_{1}$ is the total transmits power of the serving base station $\left(\mathrm{BS}_{1}\right), \mathrm{Pt}_{\mathrm{j}}$ is the total transmit power of interfering base stations $\left(\mathrm{BS}_{\mathrm{j}}\right)$ and $2 \leq \mathrm{j} \leq 7, \mathrm{~L}_{\mathrm{i} 1}$ is the propagation loss between $\mathrm{BS}_{1}$ and user $\mathrm{i}, \mathrm{L}_{\mathrm{ij}}$ is the propagation loss between $\mathrm{BS}_{\mathrm{j}}$ and user $\mathrm{i}, \alpha$ is the orthogonality factor, and $\mathrm{P}_{\mathrm{N}}$ is the background noise power at the receiver.

The noise power $P_{N}$ is assumed negligible compared with the total interference power[3] and $\mathrm{P}_{\mathrm{i} 1}$ can be resolved as follows:

$$
P_{i 1}=\frac{\mathrm{v} R_{b}}{W}\left(\frac{E_{b}}{I_{o}}\right)_{i}\left|P t_{i}(1-\alpha)+\sum_{j=2}^{7} P t_{j} \frac{L_{i 1}}{L_{i j}}\right|
$$

Assuming that all users have the same bit rate and all base stations transmit the same power level $\left(\mathrm{Pt}_{1}=\mathrm{Pt}_{\mathrm{j}}=\mathrm{Pt}\right)$, then 


$$
\left.P_{i 1}=\frac{v R_{b}}{W}\left(\frac{E_{b}}{I_{o}}\right)_{i} P t \mid(1-\alpha)+\sum_{j=2}^{7} \frac{L_{i 1}}{L_{i j}}\right]
$$

A part of the total power of the base station is dedicated for the common pilot channel $\mathrm{P}_{\mathrm{CPICH}}$ and the other part is dedicated for all users in the cell[3].

$$
\begin{gathered}
\sum_{i=1}^{I} P_{i 1}+P_{C P I C H}=\frac{v R_{b}}{W}\left(\frac{E_{b}}{I_{o}}\right) P t \sum_{i=1}^{I}\left[1-\alpha+\sum_{j=2}^{7} \frac{L_{i 1}}{L_{i j}}\right]+P_{C P I C H} \\
=P t \\
\left.P_{C P I C H}=P t \mid 1-\frac{v R_{b}}{W}\left(\frac{E_{b}}{I_{o}}\right) \sum_{i=1}^{I}\left[1-\alpha+\sum_{j=2}^{7} \frac{L_{i 1}}{L_{i j}}\right]\right)
\end{gathered}
$$

where $\mathrm{I}$ is the number of users (connections) in the cell. The power(noise) rise over the common pilot channels can be solved as follows:

$$
\begin{gathered}
N R=\frac{P t}{P_{C P I C H}}=\frac{1}{1-\frac{v R_{b}}{W}\left(\frac{E_{b}}{I_{o}}\right) \sum_{i=1}^{I}\left[1-\alpha+\sum_{j=2}^{7} \frac{L_{i 1}}{L_{i j}}\right]}=\frac{1}{1-\eta_{D L}} \\
\eta_{D L \text { noSHO }}=\frac{v R_{b}}{W}\left(\frac{E_{b}}{I_{o}}\right) \sum_{i=1}^{I}\left[1-\alpha+\sum_{j=2}^{7} \frac{L_{i 1}}{L_{i j}}\right] \\
N R(d B)=-10 \log \left(1-\eta_{D L}\right)
\end{gathered}
$$

\subsection{Analysis with SHO:}

When a mobile is located in the overlapping region of two cell as shown in figure (2), the mobile will communicate with the two cells (2-way SHO)[11]:

$$
\begin{aligned}
& \left(\frac{E_{b}}{I_{o}}\right)=\left(\frac{E_{b}}{I_{o}}\right)_{1}+\left(\frac{E_{b}}{I_{o}}\right)_{2} \\
& \left(\frac{E_{b}}{I_{o}}\right)=\frac{W}{v R_{b}}\left[\frac{P_{i 1} / L_{i 1}}{\left.P t_{1}(1-\alpha) / L_{i 1}+>_{j=2}^{7}{\frac{P t_{j}}{L_{i j}}}_{P t_{2}(1-\alpha) / L_{i 2}+\sum_{k=1}^{7} \frac{P t_{k}}{L_{i k}}}\right]}+\frac{P_{i 2} / L_{i 2}}{k \neq 2}\right]
\end{aligned}
$$

Figure (2) Soft handoff analysis 
A balance power control is used for balancing the downlink power among active set cells during soft handoff [12], this means:

$\mathrm{P}_{\mathrm{i} 1}=\mathrm{P}_{\mathrm{i} 2}$

The transmit power for each downlink channel can be expressed as:

$$
P_{i 1}=P_{i 2}=\frac{v R_{b}}{W}\left(\frac{E_{b}}{I_{o}}\right) P t\left[\frac{1}{1-\alpha+\sum_{j=2}^{7} \frac{L_{i 1}}{L_{i j}}}+\frac{1}{1-\alpha+\sum_{\substack{k=1 \\ k \neq 2}}^{7} \frac{L_{i 2}}{L_{i k}}}\right]
$$

And from [9]: $\sum_{j=2}^{7} \frac{L_{i 1}}{L_{i j}} \geq \sum_{\substack{k=1 \\ k \neq 2}}^{7} \frac{L_{i 2}}{L_{i k}}$

The same procedure can be followed for the 3-way SHO (three base stations are involved in $\mathrm{SHO})$ :

$$
\left(\frac{E_{b}}{I_{o}}\right)=\left(\frac{E_{b}}{I_{o}}\right)_{1}+\left(\frac{E_{b}}{I_{o}}\right)_{2}+\left(\frac{E_{b}}{I_{o}}\right)_{3}
$$

and

$$
\begin{aligned}
& P_{i 1}=P_{i 2}=P_{i 3} \\
& =\frac{v R_{b}}{W}\left(\frac{E_{b}}{I_{o}}\right) P t\left[\frac{1}{\left.\frac{1}{1-\alpha+\sum_{j=2}^{7} \frac{L_{i 1}}{L_{i j}}}+\frac{1}{1-\alpha+\sum_{\substack{k=1 \\
k \neq 2}}^{7} \frac{L_{i 2}}{L_{i k}}}+\frac{1}{1-\alpha+\sum_{\substack{m=1 \\
m \neq 3}}^{7} \frac{L_{i 3}}{L_{i m}}}\right]}\right.
\end{aligned}
$$

The total load factor in the cell is the sum of the load factor due to users in the non soft handoff region and due to users in soft handoff region as follows:

$$
\begin{aligned}
& \eta_{D L_{-} \text {Total }}=\eta_{D L_{-} \text {noSHO }}+\eta_{D L_{-} \text {SHO }} \\
& \eta_{D L_{\text {Total }}}=\frac{v R_{b}}{W}\left(\frac{E_{b}}{I_{o}}\right)\left\{\sum_{i=1}^{I}\left[1-\alpha+\sum_{j=2}^{7} \frac{L_{i 1}}{L_{i j}}\right]\right. \\
&\left.\left.+\sum_{n=1}^{N} \mid \frac{1}{1-\alpha+\sum_{j=2}^{7} \frac{L_{n 1}}{L_{n j}}}+\frac{1}{1-\alpha+\sum_{\substack{k=1 \\
k \neq 2}}^{7} \frac{L_{n 2}}{L_{n k}}}\right]\right\}
\end{aligned}
$$




\section{Simulation of WCDMA Parameters}

MATLAB software (version 7.4) is used to perform the simulation programs. Tables (4.1) and (4.2) list the parameters used in the simulation [3].

Table (4.1) Parameters Used in the Simulation

\begin{tabular}{|c||c|}
\hline \multicolumn{1}{|c||}{ Parameter } & Value \\
\hline \hline Total power of the base station $(\mathrm{Pt})$ & $20 \mathrm{~W}$ \\
\hline Chip rate $(\mathrm{W})$ & $3.84 \mathrm{Mcps}$ \\
\hline \hline Orthogonality factor $(\alpha)$ & 0.6 \\
\hline \hline Path loss exponent $(\mathrm{a})$ & 4 \\
\hline \hline Standard deviation of shadowing $(\sigma)$ & $8 \mathrm{~dB}$ \\
\hline \hline Soft handoff window & $6 \mathrm{~dB}$ \\
\hline Cell radius $(\mathrm{R})$ & $1 \mathrm{~km}$ \\
\hline
\end{tabular}

Table (4.2) Types of Service and the Required $E_{b} / I_{0}$

\begin{tabular}{|c||c||c|}
\hline Service type $\left(\mathrm{R}_{\mathrm{b}}\right)$ & Required $\left(\mathrm{E}_{\mathrm{b}} / \mathrm{I}_{\mathrm{o}}\right)$ & Activity factor $(\mathrm{v})$ \\
\hline \hline Voice $12.2 \mathrm{kbps}$ & $5 \mathrm{~dB}$ & 0.5 \\
\hline \hline Data $64 \mathrm{kbps}$ & $3 \mathrm{~dB}$ & 1 \\
\hline \hline Data $144 \mathrm{kbps}$ & $1.5 \mathrm{~dB}$ & 1 \\
\hline \hline Data $384 \mathrm{kbps}$ & $1 \mathrm{~dB}$ & 1 \\
\hline
\end{tabular}

Two models will be considered as shown in figure ( $2 \mathrm{a}, \mathrm{b})$ In the first model, the user moves away from its serving base station, $\mathrm{BS}_{1}$, to cell boundary $\left(r_{1}=\frac{\sqrt{3}}{2} R\right.$, $\left.\theta_{1}=0\right)$. While in the second model, the user moves away to the cell corner $\left(r_{1}=R\right.$, $\left.\theta_{1}=\frac{\pi}{6}\right)$.

Figure (3) Mobility of the User

\section{Results and Discussion}
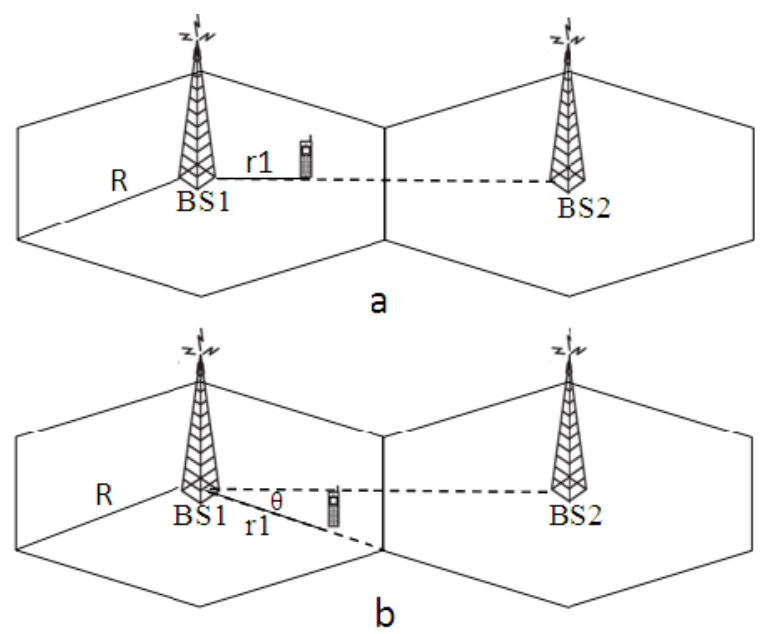

Figures (4), (5), (6), (7) show the power assigned for a user moving away from its serving BS to the cell boundary $\left(\theta_{1}=0\right)$ and figures $(8),(9),(10),(11)$ for a user moving away towards cell corner $\left(\theta_{1}=\pi / 6\right)$ for different data rates $(12.2 \mathrm{kbps}, 64 \mathrm{kbps}, 144 \mathrm{kbps}, 384 \mathrm{kbps})$. 


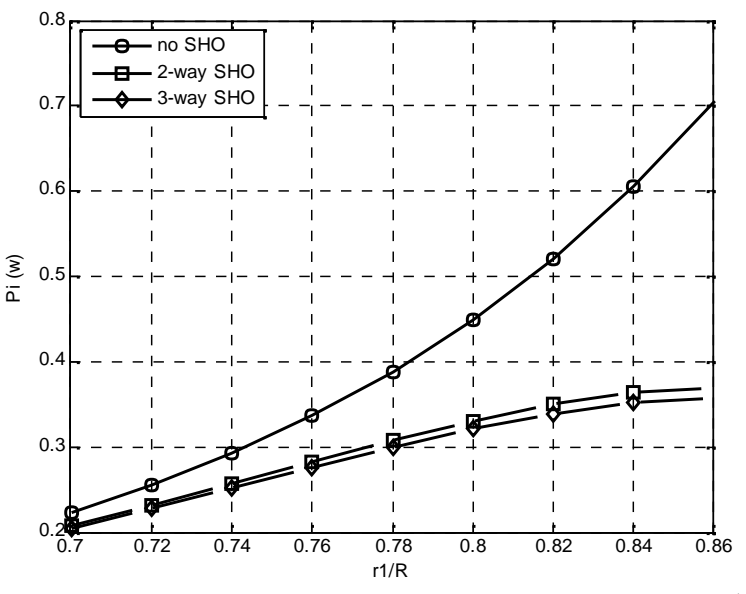

Figure (4) Power Assignment for User i $\left(R_{b}=12.2 \mathrm{kbps}, \theta_{1}=0\right)$

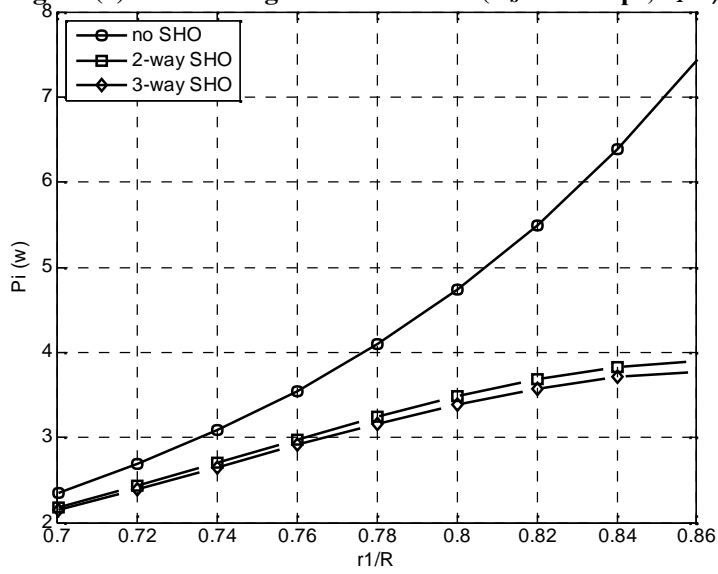

Figure (6) Power Assignment for User i $\left(R_{b}=144 \mathrm{kbps}, \theta_{1}=0\right)$

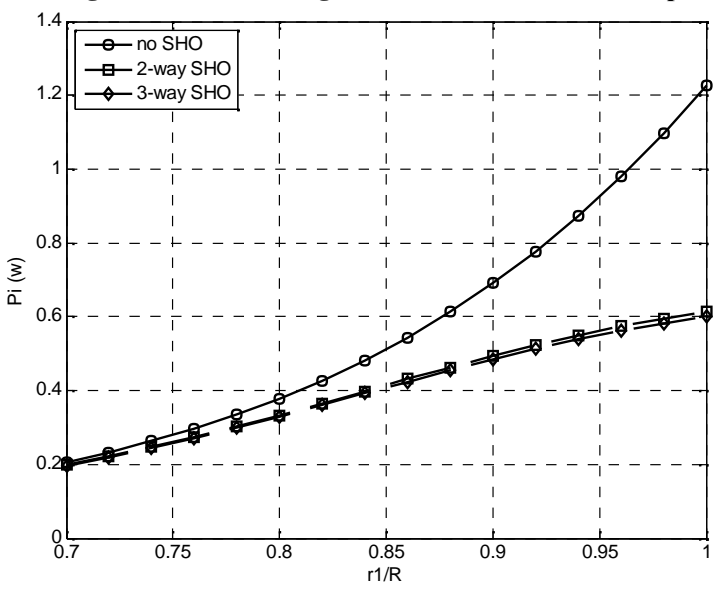

Figure (8) Power Assignment for User i $\left(R_{b}=12.2 \mathrm{kbps}, \theta_{1}=\pi / 6\right)$

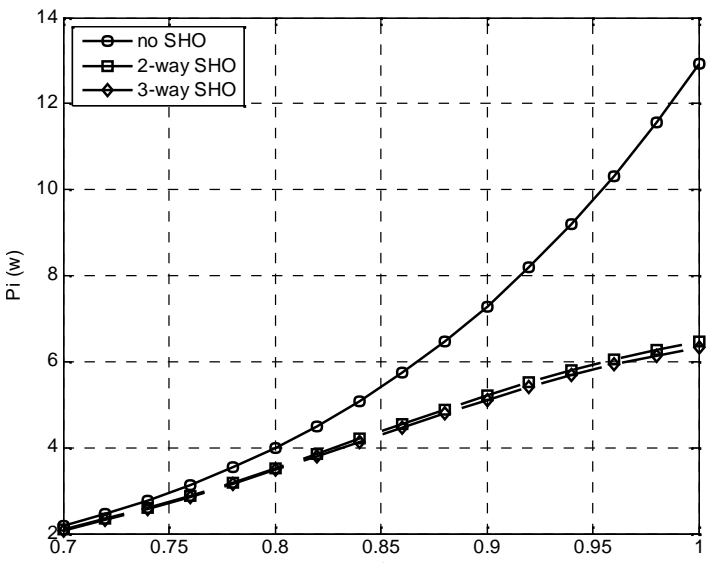

Figure (10) Power Assignment for User i $\left(R_{b}=144 \mathrm{kbps}, \theta_{1}=\pi / 6\right)$

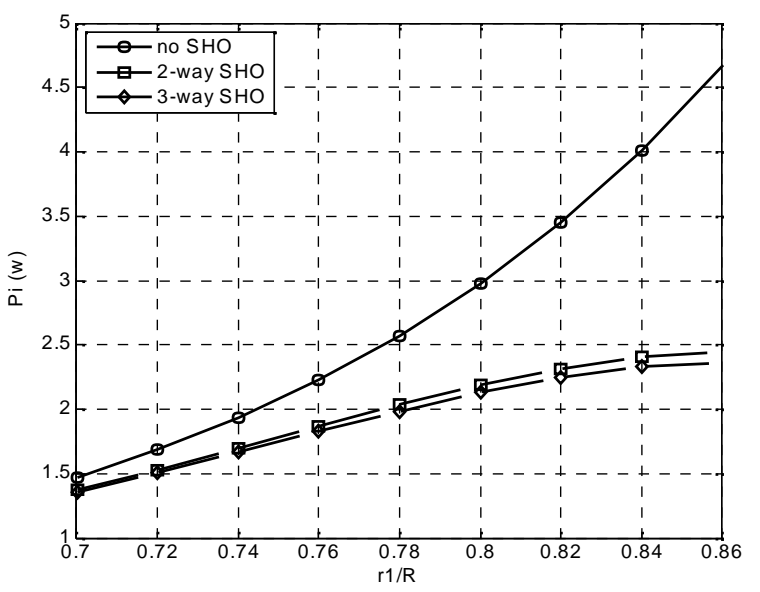

Figure (5) Power Assignment for User i $\left(R_{b}=64\right.$ kbps, $\left.\theta_{1}=\pi / 6\right)$

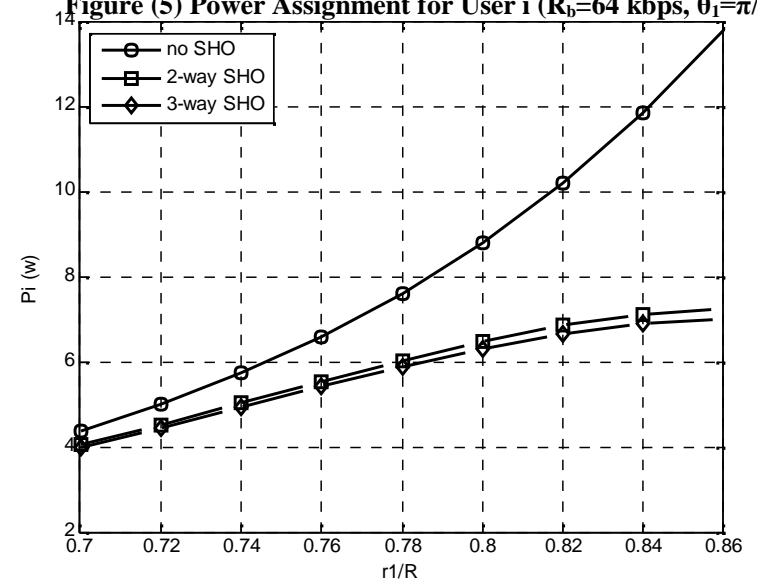

Figure (7) Power Assignment for User i $\left(R_{b}=384 \mathrm{kbps}, \theta_{1}=\pi / 6\right)$
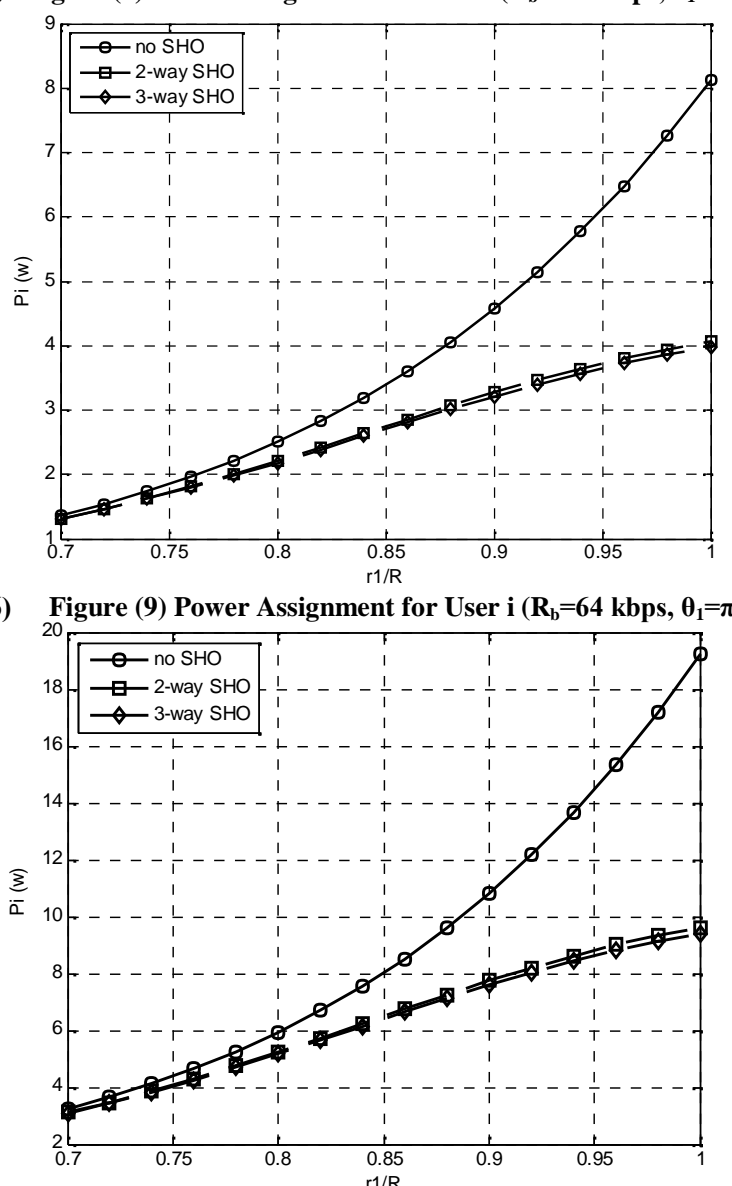

Figure (11) Power Assignment for User i $\left(R_{b}=384 \mathrm{kbps}, \theta_{1}=\pi / 6\right)$ 
The results show that soft handoff decreases the power at cell boundary and cell corner by approximately $50 \%$ (equation 15 ).

The value of $\mathrm{E}_{\mathrm{b}} / \mathrm{I}_{\mathrm{o}}$ is increased by about $3 \mathrm{~dB}$ at the cell boundary and cell corner due to implementing SHO, as shown in figures (12), (13), (14), (15) for $\theta_{1}=0$, and figures (16), (17), (18), (19) for $\theta_{1}=\pi / 6 . E_{b} / I_{o}$ is also plotted as a function the number of users, $E_{b} / I_{o}$ is decreased as the number of users is increased as illustrated in figures (36), (37), (38), (39), and $\mathrm{SHO}$ increases the $\mathrm{E}_{\mathrm{b}} / \mathrm{I}_{\mathrm{o}}$ resulting in enhancing the QoS of the system.

SHO also decreased the loading (load factor) and the noise rise in the cell as shown in figures (20), (21), (22), (23), (24), (25), (26), (27) leads to more users can be served by the cell, for voice service $(12.2 \mathrm{kbps})$ at 0.5 load factor ( $3 \mathrm{~dB}$ noise rise) the number of users without SHO is 39, while with SHO is 56 resulting in soft handoff gain about $43.6 \%$. Table (3) gives the capacity and soft handoff gain at 0.5 load factor for different data rates.

Table (3) Capacity and SHO Gain

\begin{tabular}{|c|c|c|c|}
\hline \multirow[t]{2}{*}{ Service type } & \multicolumn{2}{|c|}{ Capacity } & \multirow[t]{2}{*}{ SHO Gain } \\
\hline & Without SHO & With SHO & \\
\hline $12.2 \mathrm{kbps}$ & 39 & 56 & $43.6 \%$ \\
\hline $64 \mathrm{kbps}$ & 6 & 8.5 & $43.3 \%$ \\
\hline $144 \mathrm{kbps}$ & 3.8 & 5.4 & $42.1 \%$ \\
\hline $384 \mathrm{kbps}$ & 1.6 & 2.2 & $37.5 \%$ \\
\hline
\end{tabular}

As the user which moves away from the serving BS, the BER is increased and hence the QoS is decreased. SHO decreases the BER leads to better QoS as shown in figures (28), (29), (30), (31), (32), (33), (34), (35). The BER is also increased as the number of users is increased, in the case of voice service as shown in figure (40), without SHO and in order to meet the target BER $\left(10^{-4}-10^{-3}\right)$, the number of users is in the range $35-50$. With SHO the number of users is 57-72 to satisfy the target BER. Figures (41), (42), (43) illustrates the BER for different data rates. 


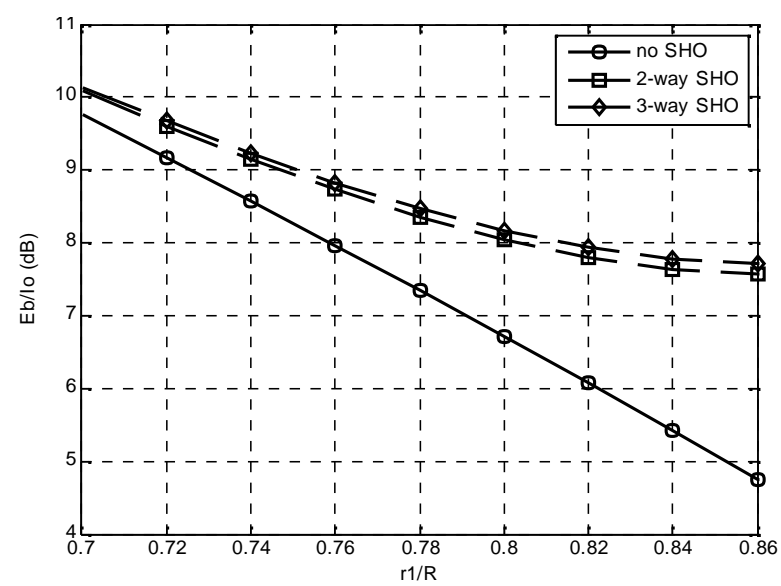

Figure (12) $E_{b} / l_{0}$ for User i $\left(R_{b}=12.2 \mathrm{kbps}, \theta_{1}=0\right)$

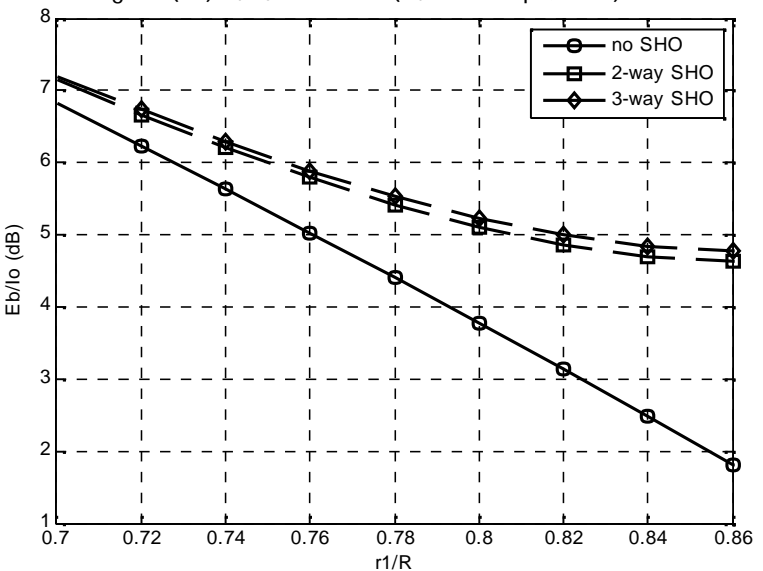

Figure (14) $E_{b} / I_{0}$ for User i $\left(R_{b}=144 \mathrm{kbps}, \theta_{1}=0\right)$
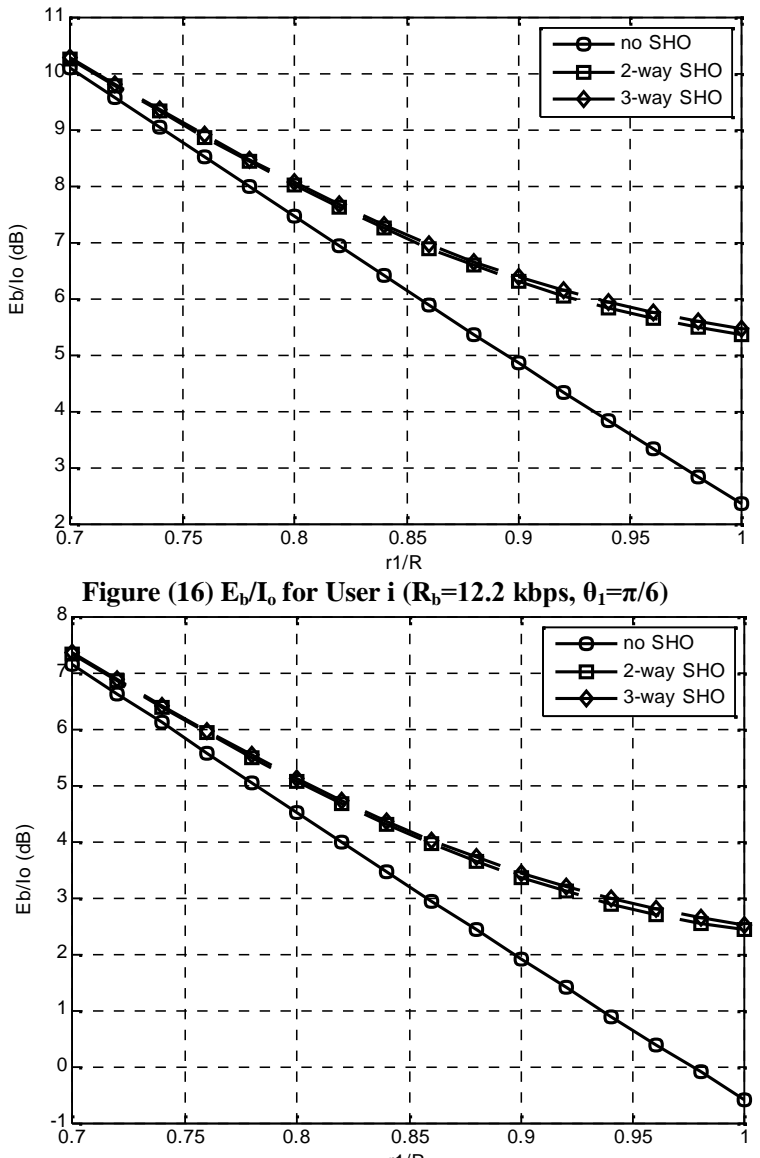

Figure (18) $E_{b} / I_{0}$ for User i $\left(R_{b}=144 \mathrm{kbps}, \theta_{1}=\pi / 6\right)$

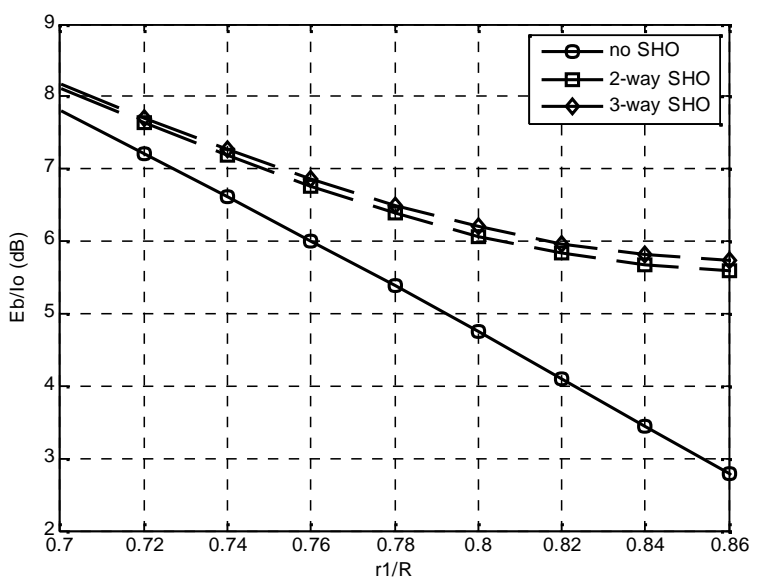

Figure (13) $E_{d} / l_{0}$ for user i $\left(R_{b}=64 \mathrm{kbps}, \theta_{1}=0\right)$

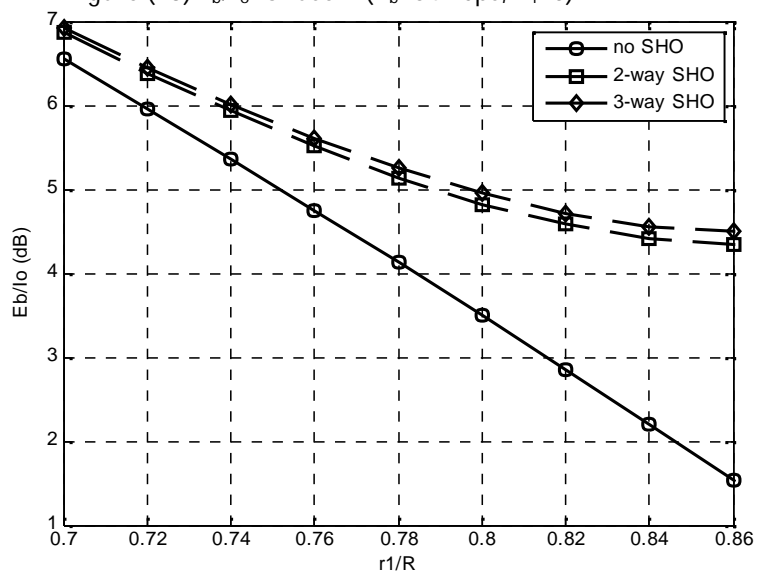

Figure (15) $E_{b} / I_{0}$ for user i $\left(R_{b}=384\right.$ kbps, $\left.\theta_{1}=0\right)$
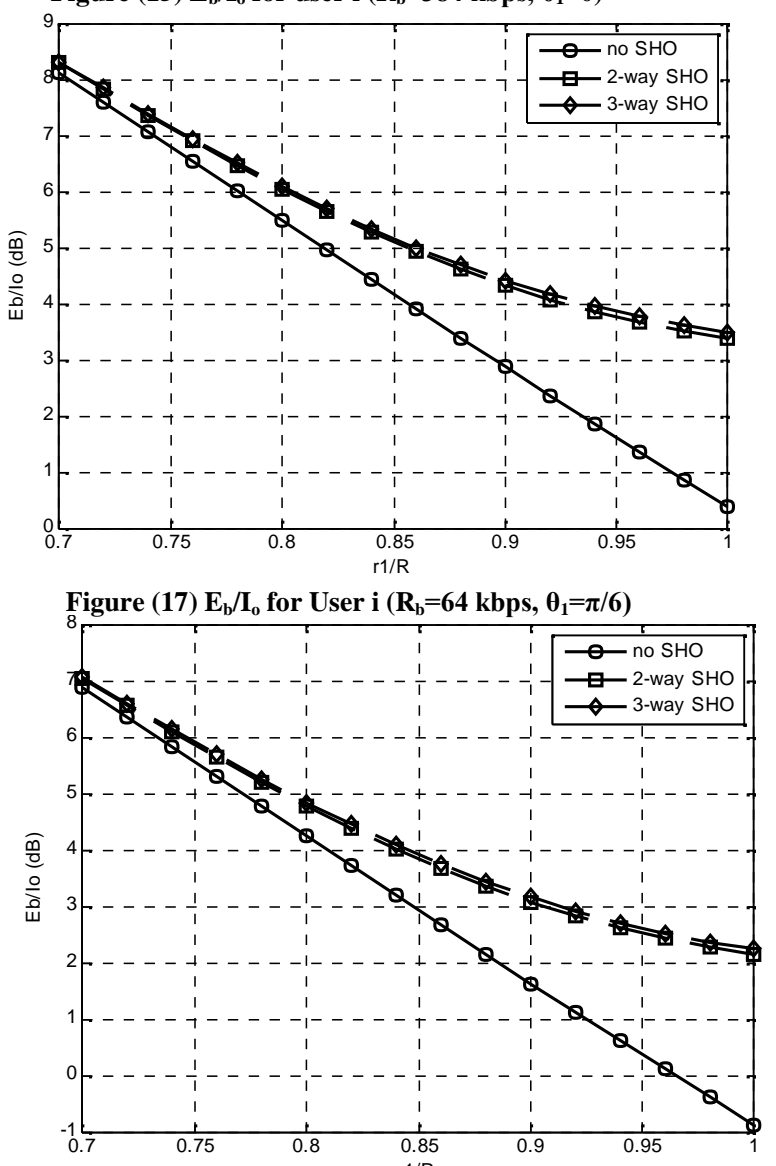

Figure (19) $E_{b} / I_{0}$ for User i $\left(R_{b}^{r 1 / R}=384\right.$ kbps, $\left.\theta_{1}=\pi / 6\right)$ 


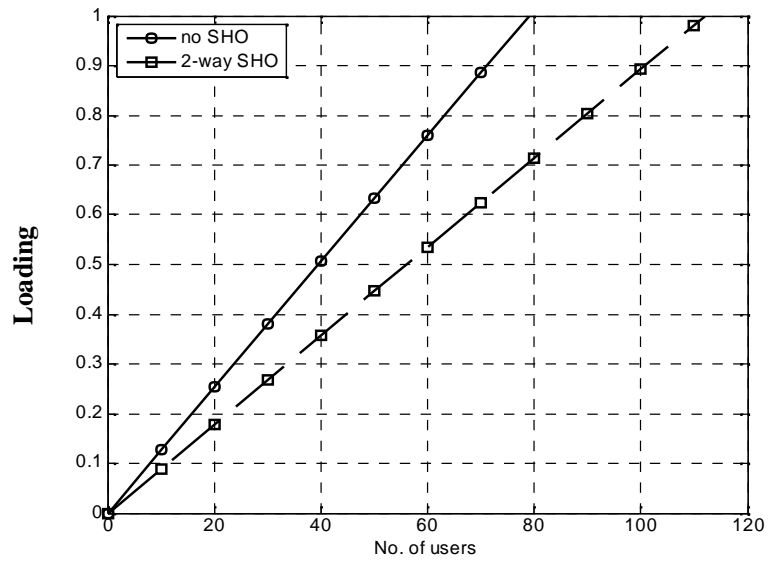

Figure (20) Downlink Load Factor $\left(\mathbf{R}_{\mathrm{b}}=\mathbf{1 2 . 2} \mathrm{kbps}\right)$

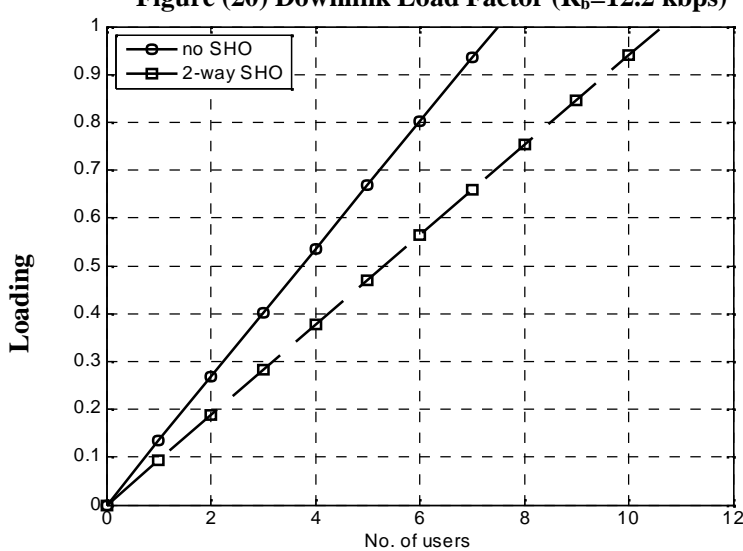

Figure (22) Downlink Load Factor $\left(R_{h}=144 \mathrm{kbps}\right)$
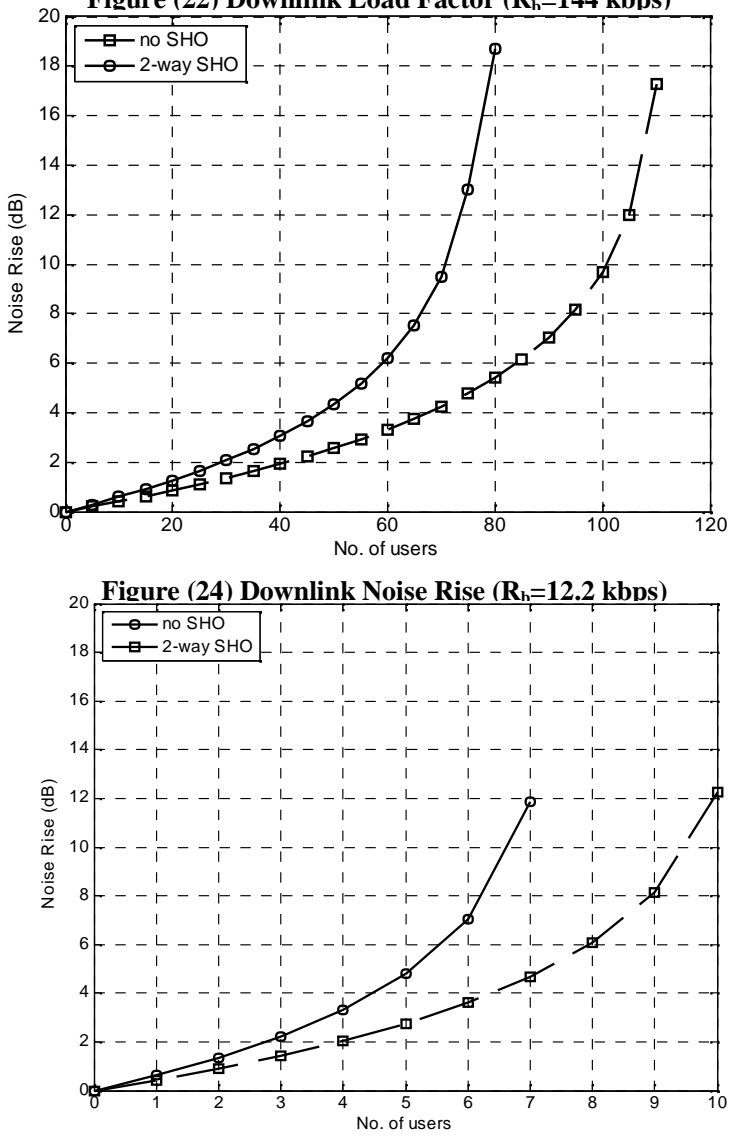

Figure (26) Downlink Noise Rise ( $R_{b}=144$ kbps)

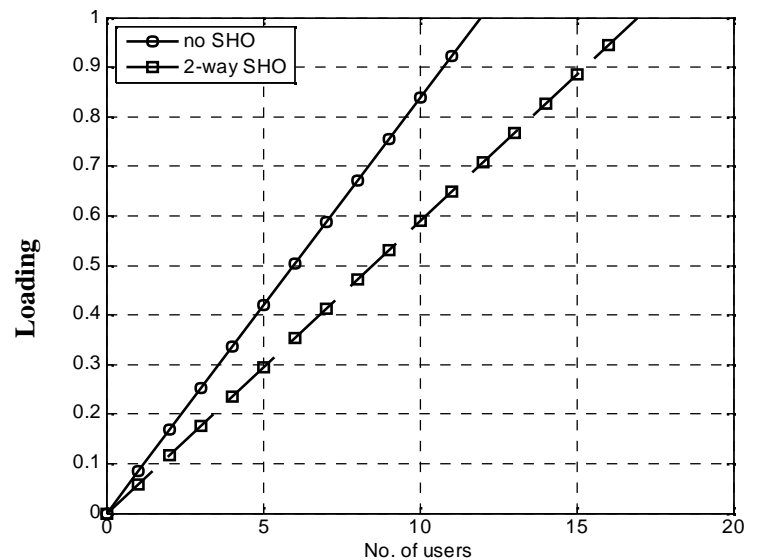

Figure (21) Downlink Load Factor $\left(\mathbf{R}_{\mathrm{b}}=64 \mathrm{kbps}\right)$
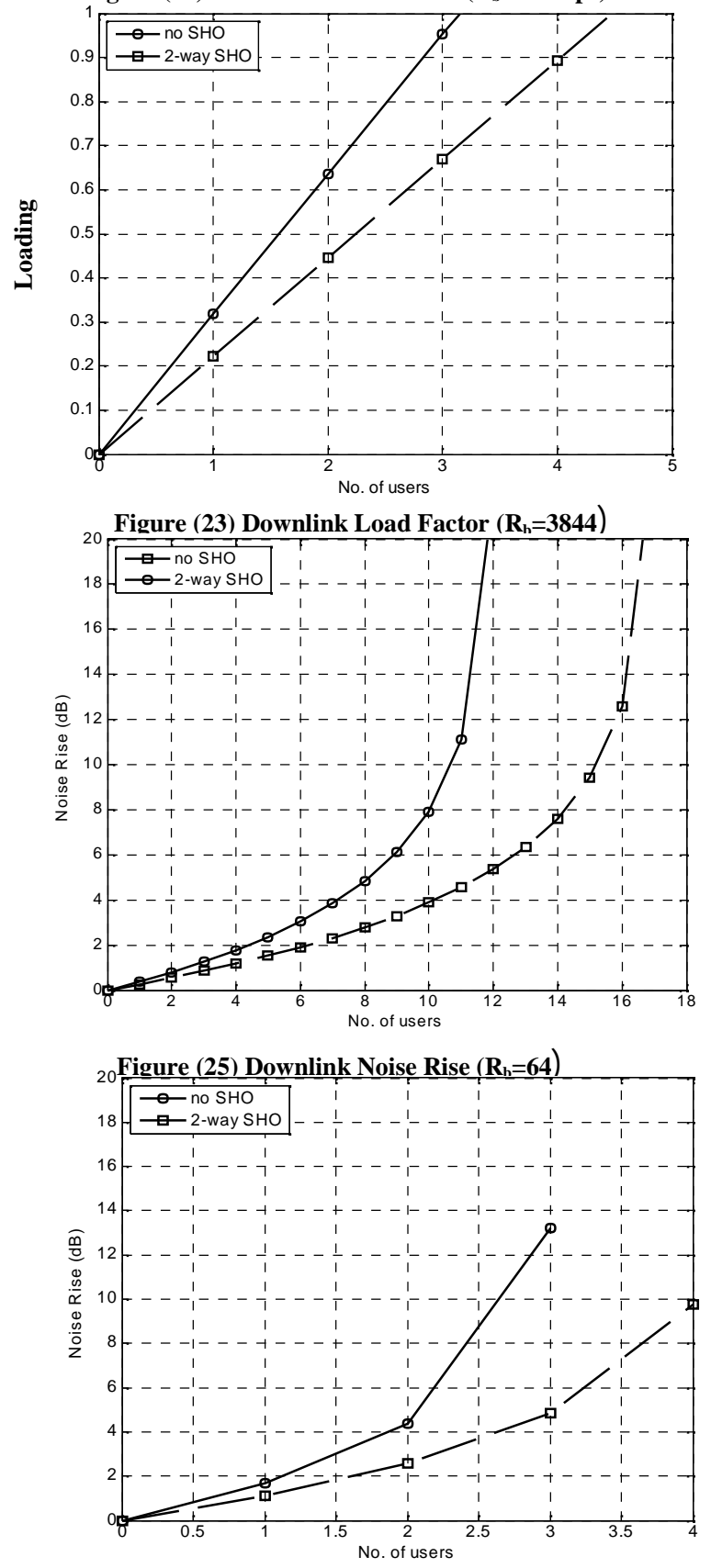

Figure (27) Downlink Noise Rise ( $\left.\mathbf{R}_{\mathrm{b}}=384 \mathrm{kbps}\right)$ 

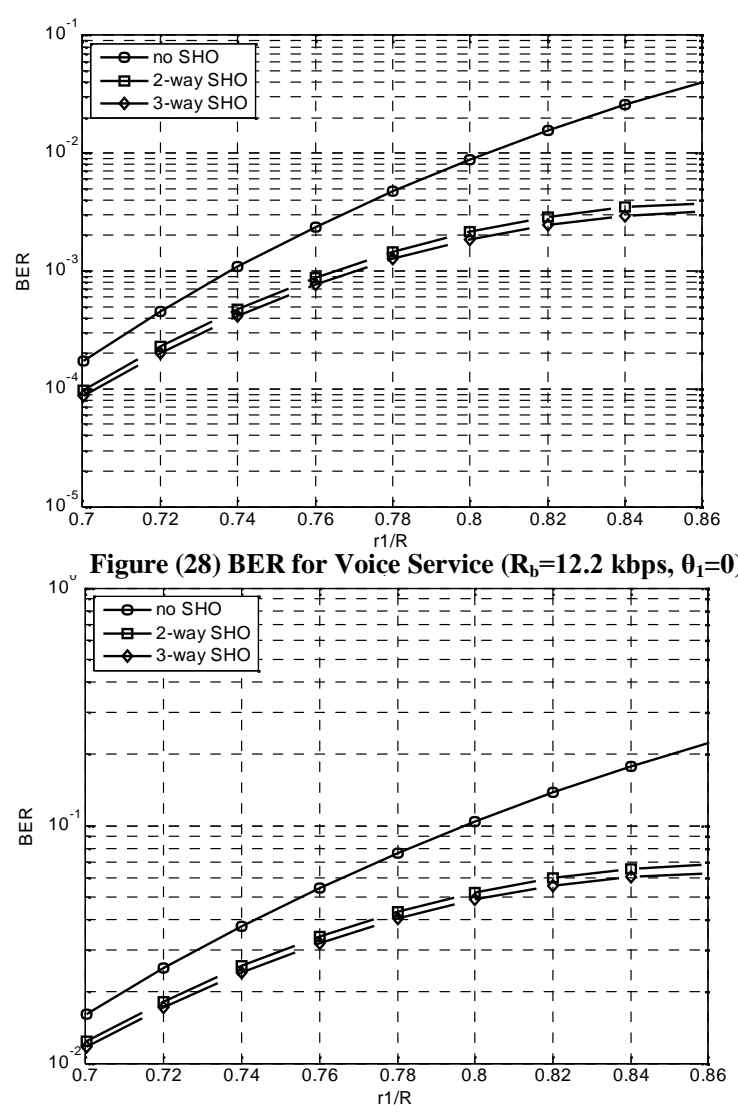

Figure (30) BER for Data Service $\left(R_{b}=144 \mathrm{kbps}, \theta_{1}=0\right)$

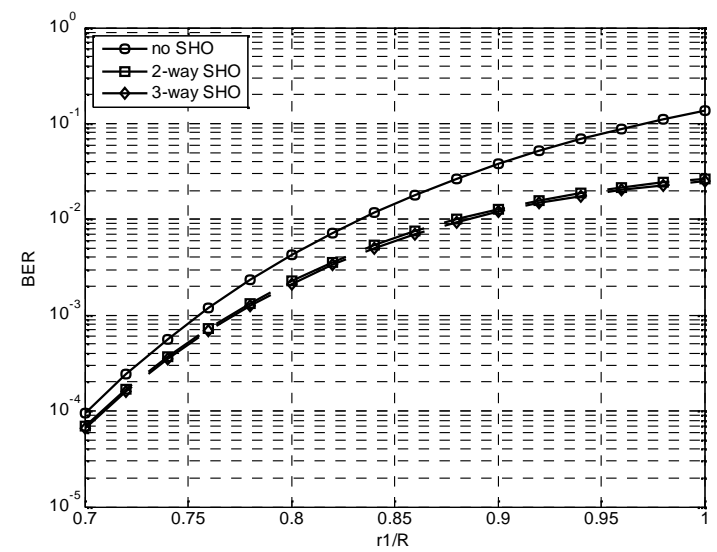

Figure (32) BER for Voice Service $\left(R_{b}=12.2 \mathrm{kbps}, \theta_{1}=\pi / 6\right)$

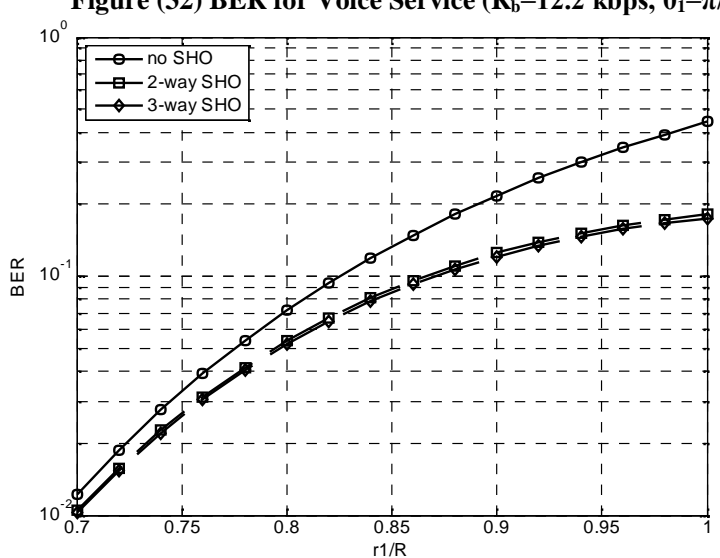

Figure (34) BER for Data Service $\left(R_{b}=144 \mathrm{kbps}, \theta_{1}=\pi / 6\right)$

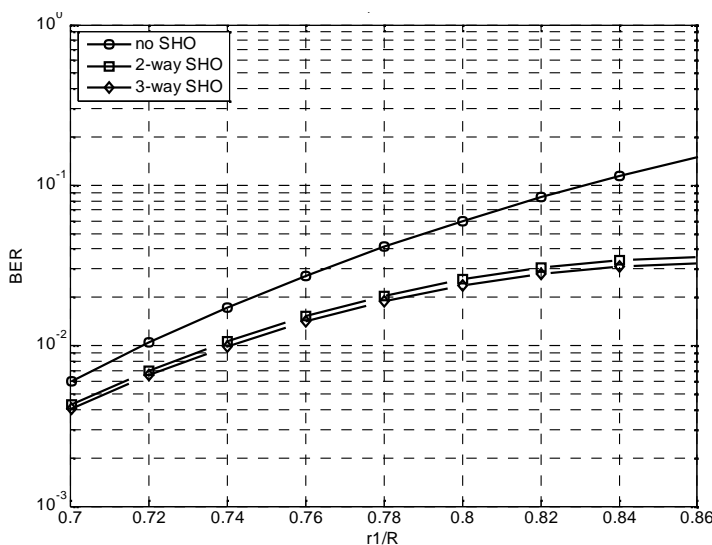

Figure (29) BER for Data Service $\left(\mathbf{R}_{\mathrm{b}}=64 \mathrm{kbps}, \theta_{1}=0\right)$

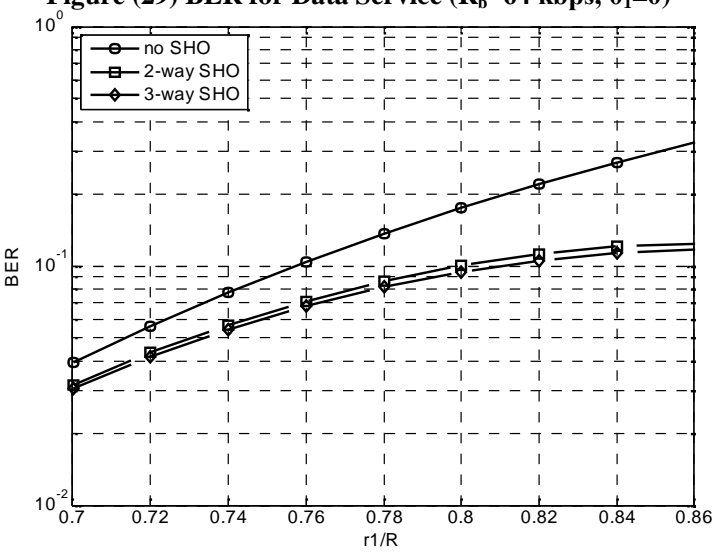

Figure (31) BER for Data Service $\left(\mathbf{R}_{b}=384 \mathrm{kbps}, \boldsymbol{\theta}_{1}=\mathbf{0}\right)$

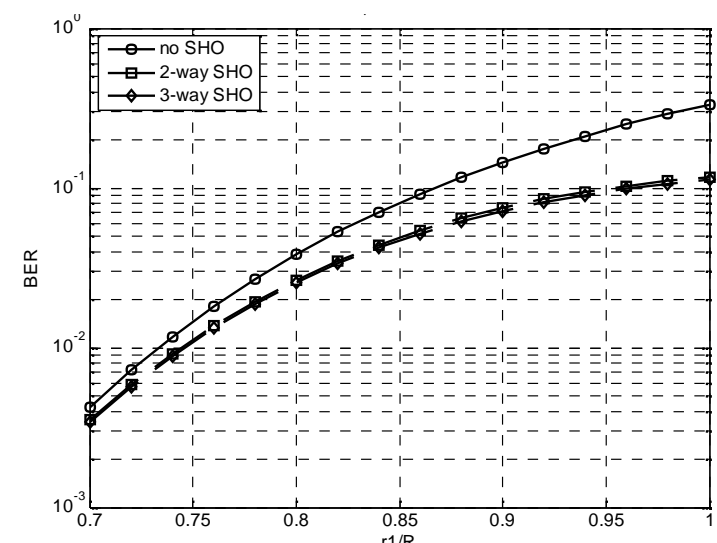

Figure (33) BER for Data Service $\left(R_{b}=64 \mathrm{kbps}, \theta_{1}=\pi / 6\right)$

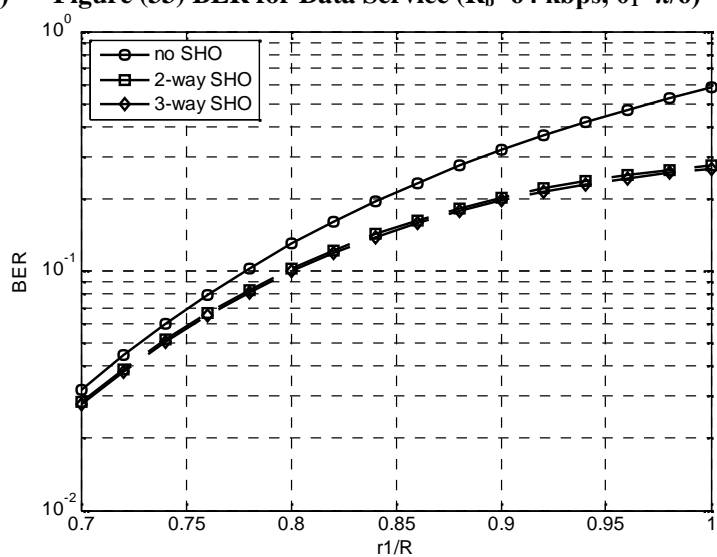

Figure (35) BER for Data Service $\left(R_{b}=384 \mathrm{kbps}, \theta_{1}=\pi / 6\right)$ 


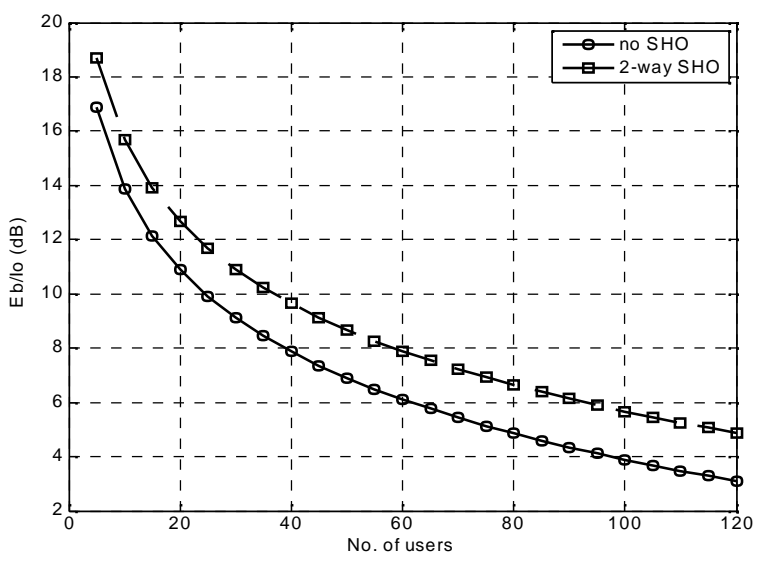

Figure (36) $E_{b} / I_{0}\left(R_{b}=12.2 \mathrm{kbps}\right)$

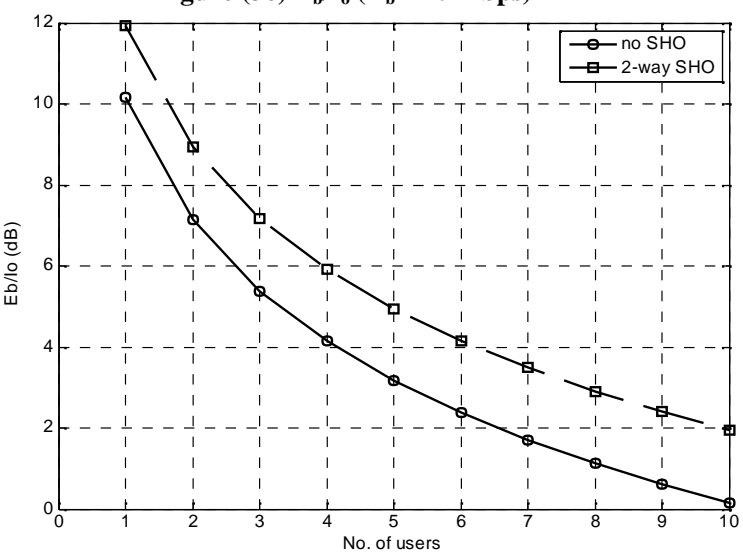

Figure (38) $E_{b} / I_{0}\left(R_{b}=144\right.$ kbps)

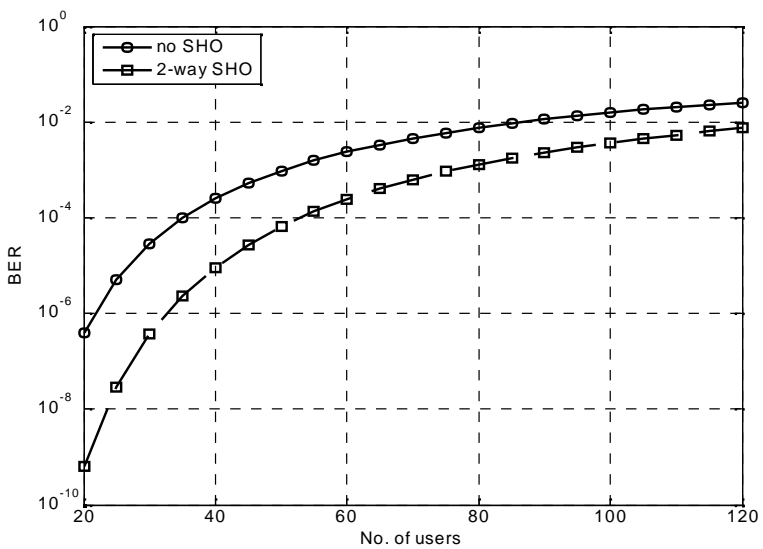

Figure (40) BER $\left(R_{b}=12.2 \mathrm{kbps}\right)$

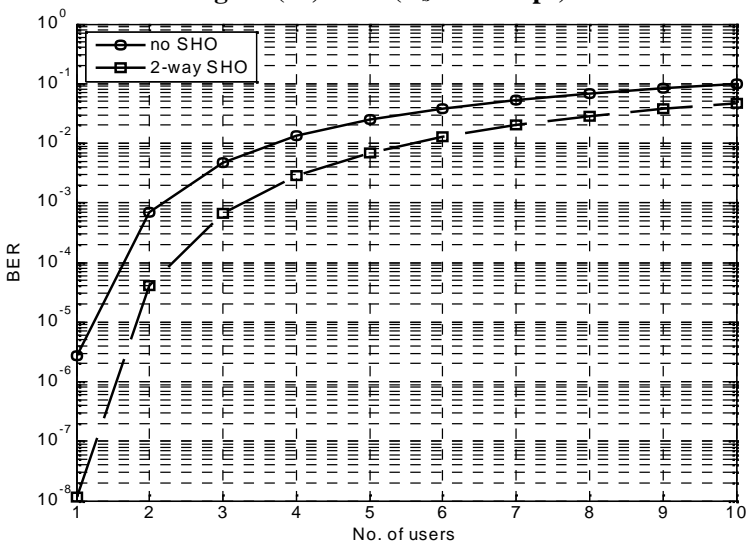

Figure (42) BER $\left(R_{b}=144\right.$ kbps)

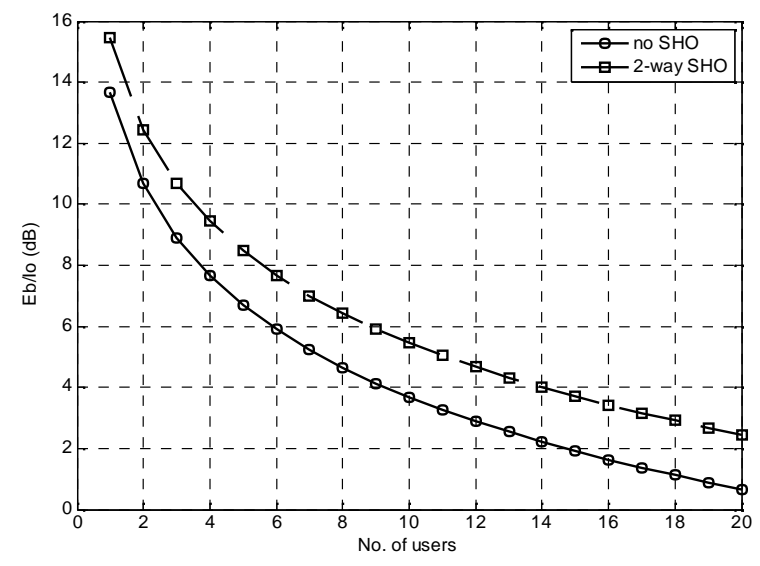

Figure (37) $\mathbf{E}_{b} / \mathbf{I}_{0}\left(\mathbf{R}_{b}=64 \mathrm{kbps}\right)$

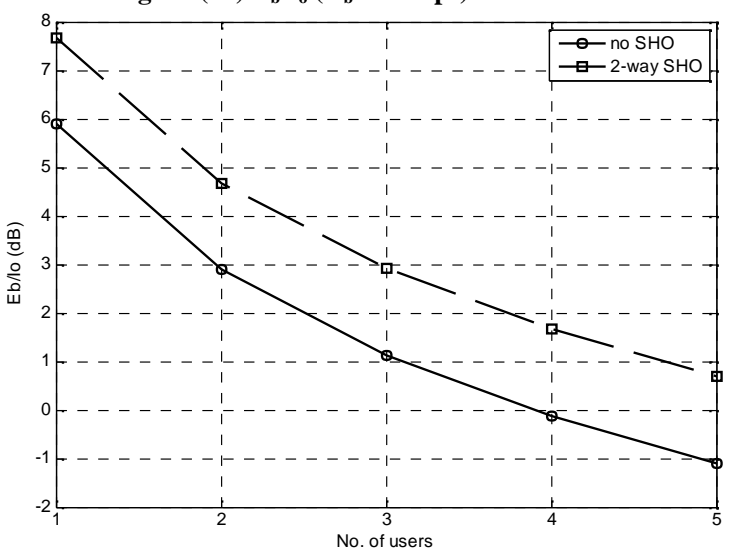

Figure (39) $\mathbf{E}_{b} / \mathbf{I}_{0}\left(\mathbf{R}_{b}=384 \mathrm{kbps}\right)$

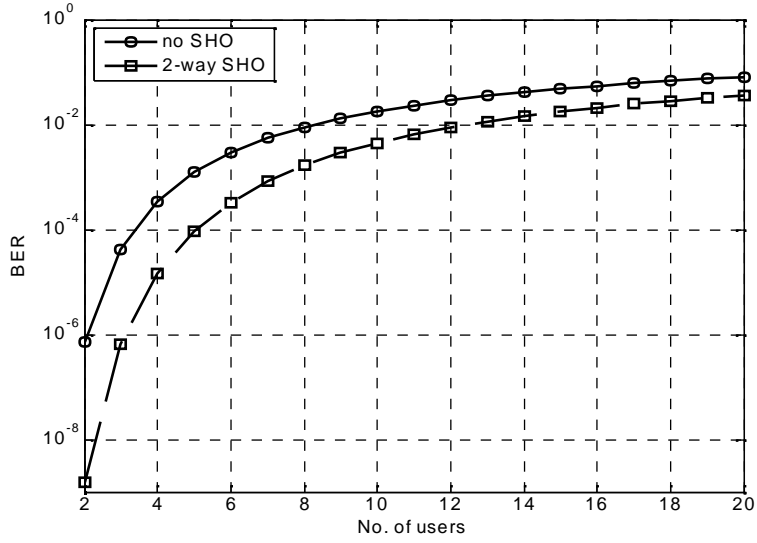

Figure (41) BER ( $R_{b}=64$ kbps)

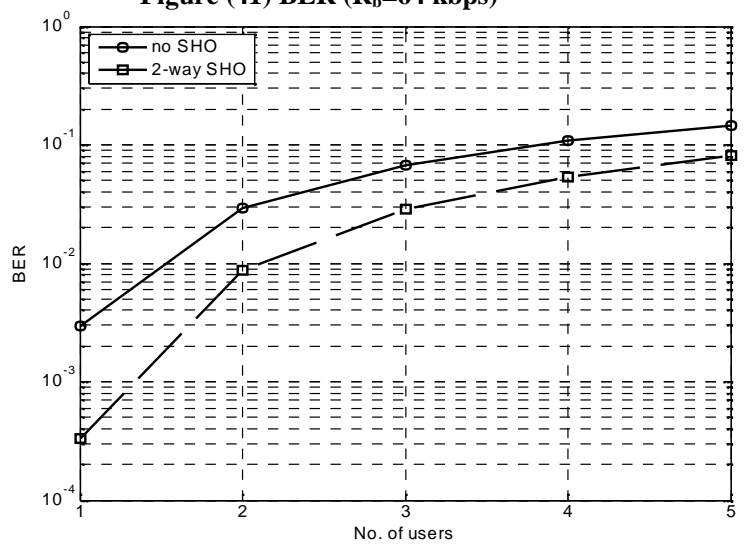

Figure (43) BER $\left(\mathbf{R}_{\mathrm{b}}=384 \mathrm{kbps}\right)$ 


\section{Conclusions}

The SHO decreases the power assignment for a user from its serving BS by approximately $50 \%$ at cell boundary and cell corner. This reduction in the power leads to decreasing the overall interference in the cell, and hence increasing the signal to interference ratio $\left(\mathrm{E}_{\mathrm{b}} / \mathrm{I}_{\mathrm{o}}\right)$. The load factor and the noise rise is also decreased when SHO is implemented resulting in increasing the number of users that can be served by the cell, this means the downlink capacity is increased. SHO gain has convergent values for different data rates. SHO improves the quality of service in terms of BER by decreasing it lower than the target value. Finally, results show a slight difference between 2-way and 3-way SHO, so 2-way SHO is used in CDMA systems.

\section{References}

[1]. J. Korhonen "Introduction to 3G Mobile Communications" , Artech House, second edition, 2003.

[2]. T. S. Rappaport, " Wireless Communication Principles \& Practice", Prentice Hall PTR, 1996.

[3]. H. Holma and A. Toskala "WCDMA for UMTS : Radio Access for Third Generation Mobile communications", John Wiley \& Sons, Ltd, Third Edition,2004.

[4]. J. Romero, O. Sallent, R. Agusti, and M. Guerra, "Radio Resource Management Strategies in UMTS", John Wiley \& Sons, 2005.

[5]. K. Sh. Zigangirar, "Theory of Code Division Multiple Access Communication", John Wiley \& Sons, 2004.

[6]. C. C. Lee, and R. Steele, "Effect of Soft and Softer Handoffs on CDMA System Capacity", IEEE, Vol. 47, No. 3, pp. 830-841, August 1998.

[7]. N. Binucci, K. Hiltunen, and M. Caselli, "Soft Handoff Gain in WCDMA", IEEE , pp. 1467-1472, 2000.

[8]. M. Ismail, and N. Aripin, "Downlink Soft handoff Performance for Different Cell Selection Schemes in WCDMA system", IEEE, pp. 808-811, 2005.

[9]. J. F. Monserrat, D. Gómez-Barquero, D. Calabuig, L. Rubio, and N. Cardona, "Evaluation of Soft Handoff Micro Diversity Gain on the UMTS System Capacity and QoS", IEEE International Symposium on Personal, Indoor and Mobile Radio Communications (PIMRC'06) 2006.

[10]. A. J. Viterbi, " CDMA : Principles of Spread Spectrum Communication", Addison-Wesley, 1995.

[11]. Y. Chen, "Soft Handoff Issues in Radio Resource Management for 3G WCDMA Network", Ph.D. Thesis, Queen Mary University of London, September 2003.

[12]. 3GPP TR 25.922, "Universal Mobile Telecommunication System (UMTS); Radio Resource Management Strategies", version 5.0.0, Release 5.

The work was carried out at the college of Engg. University of Mosul 